\title{
CAUSES OF DEATH IN 11 OF 227 PATIENTS WITH TRAUMATIC SPINAL CORD INJURY OVER PERIOD OF NINE YEARS ${ }^{1}$
}

\author{
By MARY PRICE, M.D. \\ Minneapolis, Minnesota; Assistant Professor, Department of Physical Medicine and \\ Rehabilitation, University of Minnesota; Sister Kenny Institute.
}

ANALYSIS of factors contributory to I I deaths which occurred in a group of 227 civilian patients with traumatic spinal cord injury, points out the importance of psychologic rehabilitation in handicapped patients (Table I).

The danger of death resulting from renal deterioration, respiratory insuffciency or septicaemia from neglected decubutus ulcers or urinary tract infections is of great concern to paraplegists (Tribe, I963; Barber \& Cross, I952). However, too little attention has been given to the personality traits and behavioural patterns predictive of self destructive attitudes, resulting in physical deterioration or overt suicide.

Five deaths ( 48 per cent.) among the 227 spinal cord patients observed over a period of nine years appeared to be directly attributable to problems associated with the paraplegic state: two suicide; one pneumonia with uraemia; one gramnegative septicaemia secondary to urinary tract infection; and one postural hypotension. All five individuals exhibited severe personality pathology contributory to the patients' demise.

Of the other six patients, two died of myocardial infarctions; one of stroke; one from post-surgical pneumonia; one from pneumonia with pulmonary oedema and one of accidental drowning. None were known to have serious emotional problems.

The data regarding patient deaths was obtained from hospital charts, autopsy reports, death certificates, oral and written communications from physicians or from the immediate families of the deceased.

The calculated annual death rate in the group of 227 patients was 5:2/1000/year. Although the sample is too small for accurate projection, the estimation compares with the death rate of $9 \cdot 7 / 1000$ in the general population in the state of Minnesota in 1968 (U.S. Bureau of the Census, I97I).

The five patients who died of causes attributable to paraplegia had serious personality problems best illustrated by brief case histories.

Case I. A 19-year-old $\mathrm{C}_{5}$ incomplete tetraplegic man had sustained his lesion in a car accident when he was $15 \frac{1}{2}$ years old. Prior to the accident he had been considered delinquent and had required psychiatric treatment. He had been involved with the police because of shop-lifting, drinking and the beating of a boy with a chain. He had once shot himself in the wrist. There was a question as to whether the shooting was accidental or a suicide attempt.

Intensive psychological evaluation following a post-accident suicide attempt revealed a high average intelligence, although the Trail-Making test indicated perceptual problems consistent with right hemisphere involvement. The Minnesota Multiphasic Personality

1 This research was supported in part by Research and Training Grant No. 2 from the Social and Rehabilitation Services. 


\begin{tabular}{|c|c|c|c|c|c|c|c|c|c|}
\hline \multirow{7}{*}{ 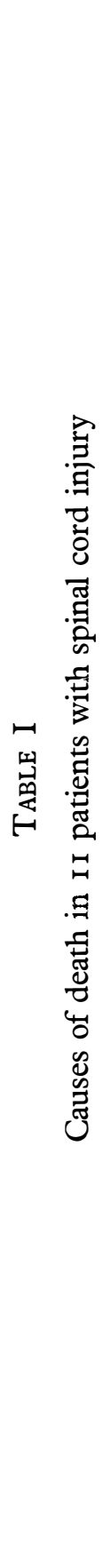 } & \multirow{2}{*}{ 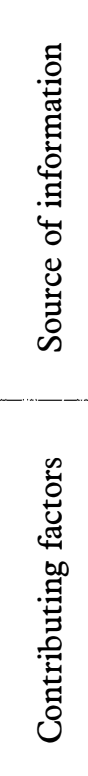 } & \multicolumn{2}{|c|}{ 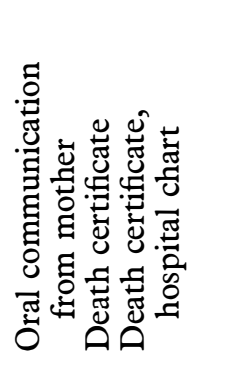 } & 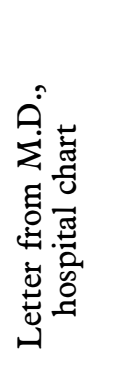 & \multicolumn{2}{|c|}{ 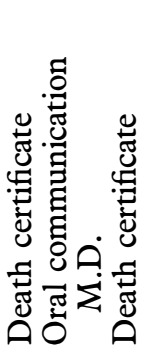 } & 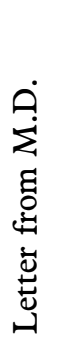 & \multicolumn{2}{|c|}{ 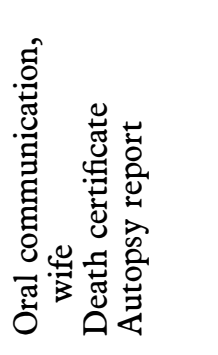 } \\
\hline & & 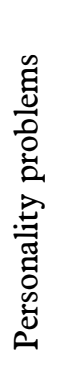 & 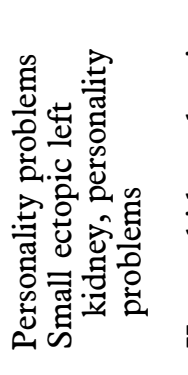 & 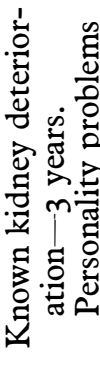 & 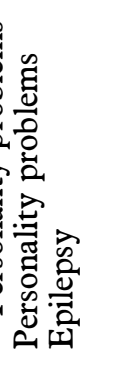 & 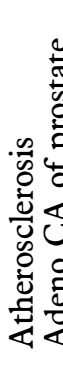 & & & \\
\hline & 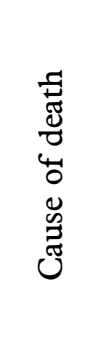 & $\begin{array}{l}\stackrel{0}{0} \\
.0 \\
.3 \\
\text { क }\end{array}$ & 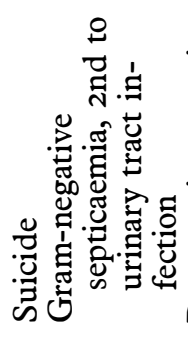 & 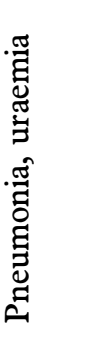 & 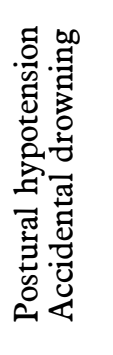 & 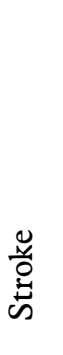 & 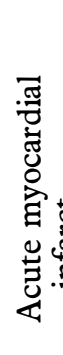 & 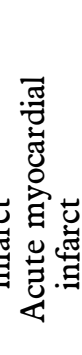 & 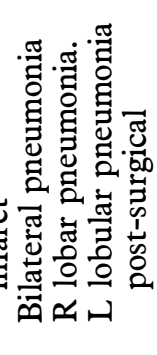 \\
\hline & 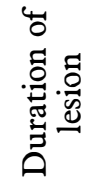 & $\underset{\substack{\infty \\
\infty}}{\infty}$ & 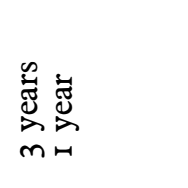 & 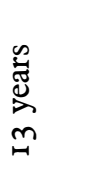 & 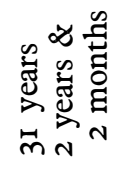 & $\overbrace{0}^{\infty}$ & 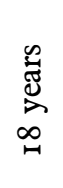 & 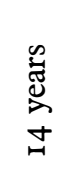 & 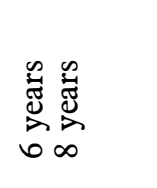 \\
\hline & 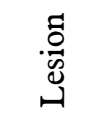 & $\begin{array}{l}\varpi \\
\mathfrak{u}\end{array}$ & $\begin{array}{l}u \cup \\
\mho \mho U\end{array}$ & $\begin{array}{l}0 \\
\tilde{\varphi}\end{array}$ & $\begin{array}{l}\mapsto \cup \\
\mapsto \leftrightarrow\end{array}$ & $\begin{array}{l}\cup \\
\stackrel{\sim}{\sim}\end{array}$ & $\stackrel{\sim}{*}$ & $\begin{array}{l}U \\
\stackrel{N}{H}\end{array}$ & 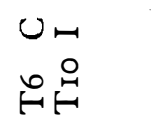 \\
\hline & 荿 & $\stackrel{બ}{a}$ & $\hat{N} \stackrel{\sigma}{ }$ & $\bar{m}$ & 字亩 & 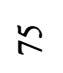 & $\bullet$ & $\dot{m}$ & 충 \\
\hline & 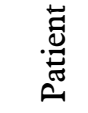 & $T$ & $N m$ & $\nabla$ & $n \sigma$ & $r$ & $\infty$ & $a$ & 옴 \\
\hline
\end{tabular}


Inventory (MMPI) suggested an overactive, impulsive, distractive individual with paranoid tendencies.

Rehabilitation was attempted at two reputable institutions with poor results. The patient's motivation seemed low and there was friction with the staff at both hospitals. Death was by self-inflicted gunshot wound.

Case 2. The patient was an attractive, intelligent 27-year-old female college graduate who became tetraplegic following an automobile accident. Before injury she had been a social non-conformist. She had held jobs as a waitress and a geology technician, and had said that she liked to work 'among' people but not with them. The interpretation of her MMPI reveals a narcissistic person interested in physical activity, who thought of herself as unlike other people and deserving of treatment different from that given to others. During her hospitalisation she was considered suicidal. After discharge there was one re-admission to protect her from suicidal proclivities. Death was due to drug overdosage.

Case 3. A I9-year-old man of bright normal intelligence dived into shallow water with resulting C6 complete tetraplegia. Although his MMPI was interpreted as normal, he became withdrawn and was uncooperative with the nursing and therapy staff. He frequently refused to talk. When it was explained that healing of decubiti in part depended on his achieving a normal serum protein level, he stated that he was a vegetarian although his family did not corroborate this statement. He was disinclined to follow advice regarding the care of his urinary tract although he was aware of the added hazard resulting from a poorly functioning ectopic right kidney. Suicidal wishes were verbalised prior to discharge. Death was due to gram-negative shock secondary to a urinary tract infection.

Case 4. A 3 I-year-old male had incurred a $\mathrm{T}_{5}$, complete spinal lesion in an auto accident 13 years prior to his death. His initial rehabilitation was stormy because of his rebellious reaction to all authority figures. His IQ was estimated at 94. His MMPI profile was described as one 'apt to be found among psychiatric patients carrying the diagnosis of hypomania'. It was suggested that management might be difficult because of over-activity, over-talkativeness and 'truly bizarre' ideas.

This patient developed many decubiti, some of which resulted in osteomyelitis. His nutrition was poor, in part due to reliance upon alcoholic beverages. For the last three years of his life he was known to have severe deteriorated kidney function. When he developed pneumonia, he quickly went into uraemia and died.

Case 5. This 47-year-old woman had sustained a $T_{I}$ incomplete paraplegia as the result of an auto accident at the age of 16 years. Because of her depression and need for attention she developed a demanding, hyperitical way of life which resulted in almost complete rejection by family and friends. She moved from one nursing home to another because of her inability to get along with staff personnel. Her MMPI profile was interpreted as that of an immature, self-centred, demanding individual with little insight into her behaviour. Efforts at behaviour modification were only partially successful. Her death occurred in a nursing home where the modification programme was being continued. The autopsy report resulted in certification of death due to postural hypotension.

The six other deaths were not aetiologically associated with the spinal cord injury and there was no documentation of serious personality defect among these patients.

Case 9 was a 34-year-old T2 complete paraplegic man who succumbed to a myocardial infarction. He had a good work record and was able to support a wife and two children with a minimum of welfare aid. 
Case II was a 40-year-old woman who, although neglectful of self-care, was known to have had cardio-pulmonary difficulties prior to her injury. The post-surgical pneumonia responsible for her death is unlikely to have been relative to her incomplete Tio neurologic deficit.

Case 6. An I8-year-old T8 complete paraplegic man drowned during an epileptic seizure. His spinal cord lesion was incurred after falling out of a tree, presumably during a seizure.

Case 7 was a 75-year-old L2 complete paraplegic who died of a stroke. Case 8 was a 66-year-old TI2 incomplete paraplegic man who succumbed to a myocardial infarct and Case 10 was a 7I-year-old man who died because of bilateral pneumonia.

The primary concern for patients with spinal cord injury had traditionally been focussed upon physical and vocational rehabilitation. The importance of these facets of rehabilitation is undeniable. However, the influence of emotional disability upon the cause of death in six of I I patients, emphasises the need for the better use of available methods of prediction and the development of new tools for coping with the emotional needs of the severely handicapped.

\section{SUMMARY}

Various causes of death in I I patients with long-standing spinal injuries ranging from $\mathrm{C}_{5}$ to Tio are described. Only one died from septicaemia due to urinary tract infection. The analyses of the causes point out the importance of psychological rehabilitation in paraplegics.

\section{RÉSUMÉ}

Les différents causes de décès ont été étudiées dans onze lésions médullaires traumatiques chroniques de $\mathrm{C}_{5}$ à Thıo. Un seul décéda de septicémie après infection urinaire. L'analyse des causes montra l'importance de la réadaptation psychologique chez le paraplégique.

\section{REFERENCES}

Tribe, C. R. (1963). Causes of death in the early and late stages of paraplegia. Paraplegia, I, I9-47 (Stoke Mandeville).

BARBER, K. E. \& CROSS, R. R. (I952). Urinary tract as cause of death in paraplegia. $\mathcal{F}$. Urol. 67, 494-502.

U.S. Bureau of the Census, Statistical Abstract of the United States. (i97i). 92nd Edition. Washington. 